\title{
Nano Composite Photoactive P-N Junction Blend for Plastic Solar Cell
}

\author{
Ishwar Naik $^{\mathrm{a}^{*}}$, Rajashekhar Bhajantri $^{\mathrm{b}}$ \\ $a^{a^{*}}$ Asst. Professor in Physics, Govt. Arts \& Science College, Karwar. \\ ${ }^{b}$ Professor, Dept of Physics, Karnatak University, Dharwad.
}

\begin{abstract}
Presently we have doped $\mathrm{TiO}_{2}$ nano particles (particle size $<100 \mathrm{~nm}$ ) as $\mathrm{N}$ type semiconductor onto $P$-type organic semiconductor Poly [2-methoxy-5-(2'-ethylhexyloxy)-phenylene vinylene] (MEH-PPV). Numerous $P-N$ junctions are created at the interface of nanoparticle and polymer matrix forming a bulk hetero junction photoactive blend. The donor MEH-PPV polymer matrix is modulated by adding $\mathrm{TiO}_{2}$ nano particles at 3:1, 1:1 and 1:3 weight ratio in Chloro-Benzene (CB) as the solvent and glass-coated nanocomposite films are prepared by solution cast method. The samples are analyzed by JASCO UV Vis NIR V 670 spectrometer. With the increased weight content of $\mathrm{TiO}_{2}$ in the composite, broadening of absorption curve is observed indicating the reduction in the band gap .Onset wavelengths determined from Tauc's plot for 3:1, 1:1, 1:3 P-N junctions are $589.62 \mathrm{~nm}, 605.32 \mathrm{~nm}, 619.96 \mathrm{~nm}$ with respective band gaps of 2,1eV, 2.04, $2.07 \mathrm{eV}$. Among the samples, 1:3 composite has the broad spectral sensitivity for absorption and considered as the best photoactive blend. Fluorescence study is also carried at an exciting wavelength of 340nm and the samples are emissive at about $590 \mathrm{~nm}$. The Intensity of emission decreases with increase in the doping level of nano particles indicating the quenching of fluorescence with nano concentration. Quenched fluorescence enhances the photon dissociation as charged carriers. SEMimages confirmed the formation of P-N junctions and XRD studies account for the semicrystalline character of the blend. Construction of the solar cellwith the optimized 1:3 MEH:TiO2 blend is the work under progress.
\end{abstract}

Keywords: $M E H-P P V, H O M O, L U M O$

\section{Introduction}

Harvesting the solar energy through solar cells is the powerful solution to energy crisis due to which the organic photovoltaics has become a highly popular research topic of the present day [1]. Although the Conventional solar cells that are made up of inorganic $\mathrm{P}$ and $\mathrm{N}$ type semiconductors like Silicon and Germanium have enough efficiency, they are not affordable to common people.These first generation silicon based cells suffer from material cost, installation cost and fabrication complications. The second generation cells are the thin film cells based on $\mathrm{Si}$, CdTe etc . The advantage of these solar cells is that they can be fabricated on all substrates and even on flexible substrates. The material cost is drastically reduced relative to the first generation cells. The main disadvantage of thin film solar cells is that their efficiency is lower than the first generation solar cells and processing cost is more[2]. The third generation solar cells make use of organic semiconductors like conducting polymers or small molecules. The branch has been developed since the invention of conjugated polymers. The use of nano particles and dyes have improved the performance of the third generation organic photovoltaic devicesed to be the promising devices in this direction. Organic solar cells are inexpensive and more advantageous due to light weight, flexibility along with ease processing ability. They are widely investigated at scientific and industrial level $[3,4,5,6]$. Unlike inorganic or conventional solar cells , these organic solar cells are made up of organic $\mathrm{P}$ and $\mathrm{N}$ type materials. Organic solar cells can be classified as single layer cells, Bilayer cells, Bulk heterojunction cells, Multilayer cells and Plasmonic cells. This constructional hierarchy is the the result of progress in constructing an efficient solar cell by the researchers.. But construction of an efficient and durable organic solar cell (plastic solar cell) is still a global challenge for Scientists.. Nanotechnology assisted plastic electronics can be the effective solution in this regard. The use of nano technology has laid a strong hope in the field of organic electronics. Semiconductor nanocrystals act as electron acceptors due to their higher electron affinity that can be used for preparing the photoactive blend with donor type conducting polymers .

Preferably semiconducting nano particles like zinc oxide and $\mathrm{TiO}_{2}$ can be used as electron accepting (N-type) materials with P-type organic polymers(donors). Nano particle doped $\mathrm{P}$ type conducting polymers will act as an efficient mixed junction photoactive material for solar cells. Large number of P-N junctions will be created at the interface of polymer and nano particles ( $\mathrm{N}$ type)embedded in it. The large surface to volume ratio of nano particles is effective in creating large P-N junction interfaces. In the present work we have prepared

International Conference on Recent Innovations in Civil \& Mechanical Engineering $\quad 93 \mid$ Page [i-CAM2K16] DOI: 10.9790/1684-16053029396 
mixed junction photo active blend of TiO2 doped Poly [2-methoxy-5-(2'-ethylhexyloxy)-phenylene vinylene] and the samples of different P:N weight ratios are characterized by UV-Visible spectra for optimizing the weight ratio for maximum absorption of solar energy. The onset wavelength and Band Gap values are determined by plotting Tauc's curves. The samples are also characterized by Fluoroscence Spectrometer to investigate the effect of nano doping on the light emission property of the blend. XRD and SEM studies are also carried out.

\section{Experimental}

The P-type donor polymer MEH-PPV (mol.wt.40000-70000, HOMO $5.3 \mathrm{eV} \mathrm{\&} \mathrm{LUMO} 3.0$ eV) Sigma Aldrich Corporation. $\mathrm{TiO}_{2}$ nano particles ( mixture of rutile \& anatase), particle size < 100nm(BET), $<50 \mathrm{~nm}(\mathrm{XRD})$ is also procured from Sigma Aldrich. The solvent Chloro-benzene (mol.wt.112.56) is from (Rankem Chemicals) RFCL limited, All the chemicals are used as received without further purification.

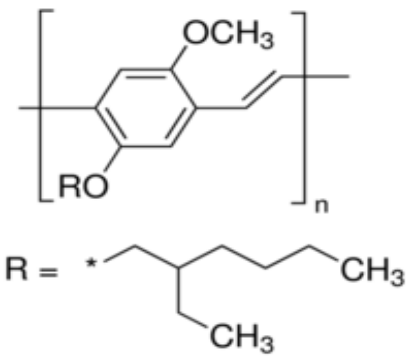

Figure 1 structure of MEH-PPV

20mgof MEH-PPV is added to $125 \mathrm{cc}$ of chlorobenzene andf magnetically stirred for $24 \mathrm{hrs}$ at room temperature to ensure the formation of uniform solutions. The solutions are added with $0.5 \mathrm{mg}, 1.0 \mathrm{mg}$ and $1.5 \mathrm{mg}$ of $\mathrm{TiO} 2$ directly in separate beakers and magnetically stirred for about12 hours to ensure the optimum dispersion of nano particles in the polymer matrix. The doped solutions are transpired to petri plates and dried in oven at 40 degree centigrade. The glass coated samples are subjected for characterization and analyzed.

Table 1 Sample Composition

\begin{tabular}{|l|l|l|}
\hline P type solution MEH-PPV/CB & TiO2 & Doping state \\
\hline $1.5 \mathrm{mg}(9.4 \mathrm{cc})$ & $0.5 \mathrm{mg}$ & $3: 1$ \\
\hline $1 \mathrm{mg}(6.25 \mathrm{cc})$ & $1.0 \mathrm{mg}$ & $1: 1$ \\
\hline $0.5 \mathrm{mg}(4.13 \mathrm{cc})$ & $1.5 \mathrm{mg}$ & $1: 3$ \\
\hline
\end{tabular}

\section{Result And Discussion}

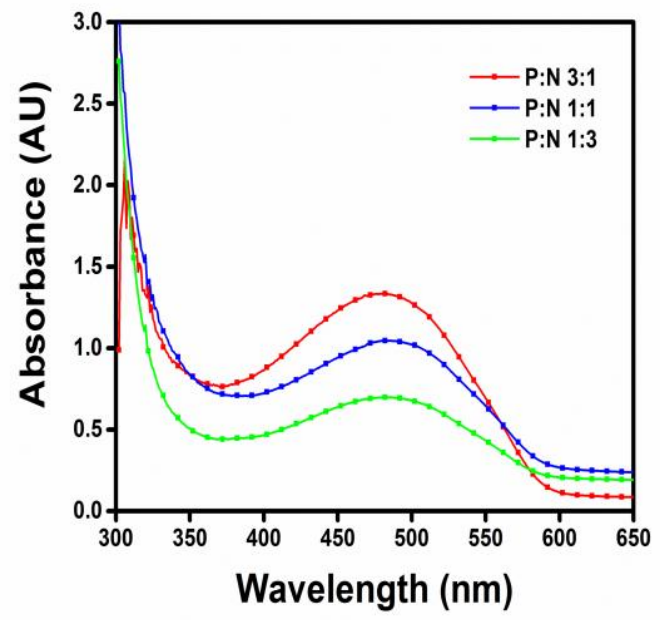

Figure 2 Overlay of absorption Spectra

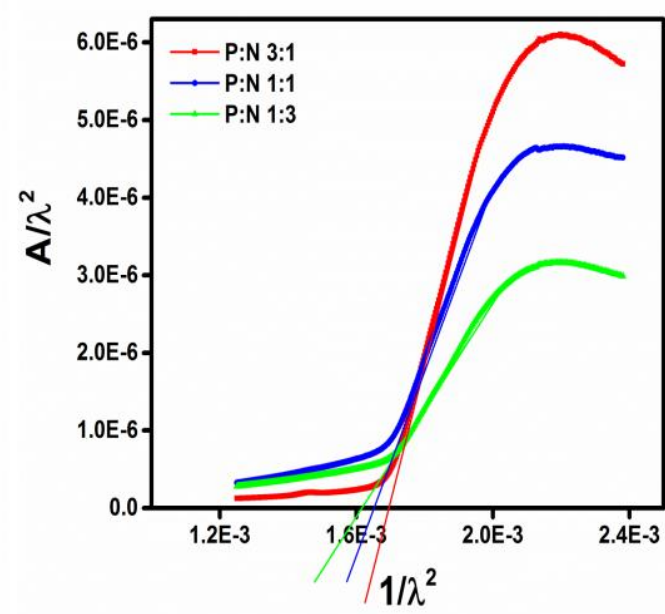

Figure 3 Overlay of Tauc's plot 


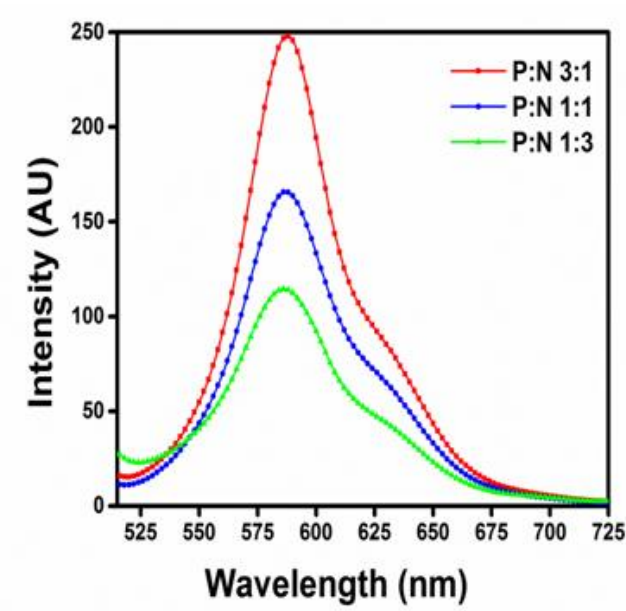

Figure 4 Overlay of Emission Spectra

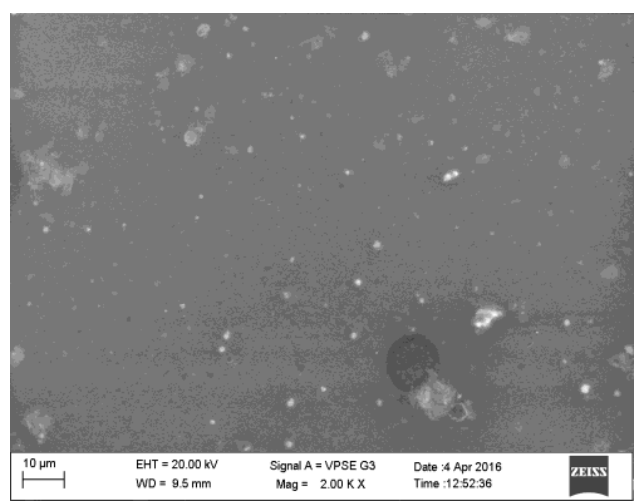

Figure 6 SEM image of 3:1 P:N Blend

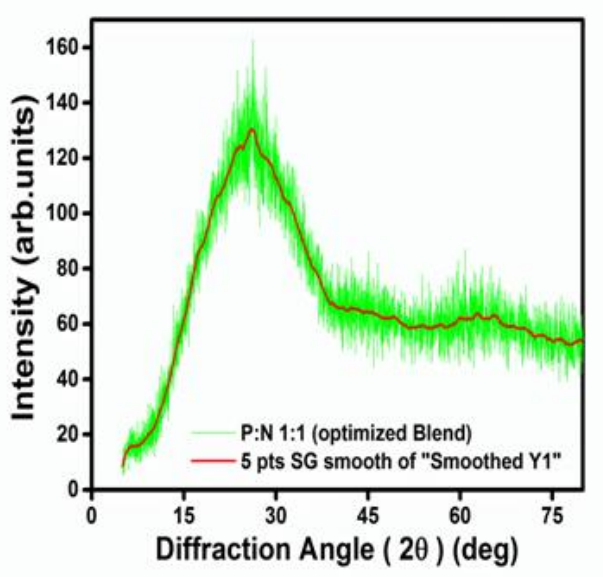

Figure 5 XRD of 1:3 Sample

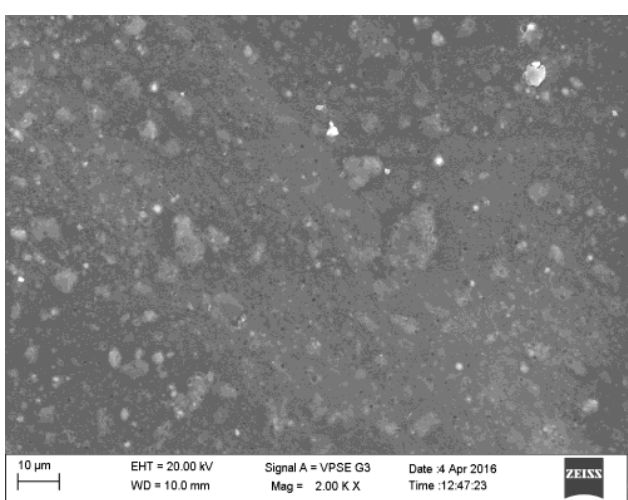

Figure 7 SEM image of 1:1 P:N Blend

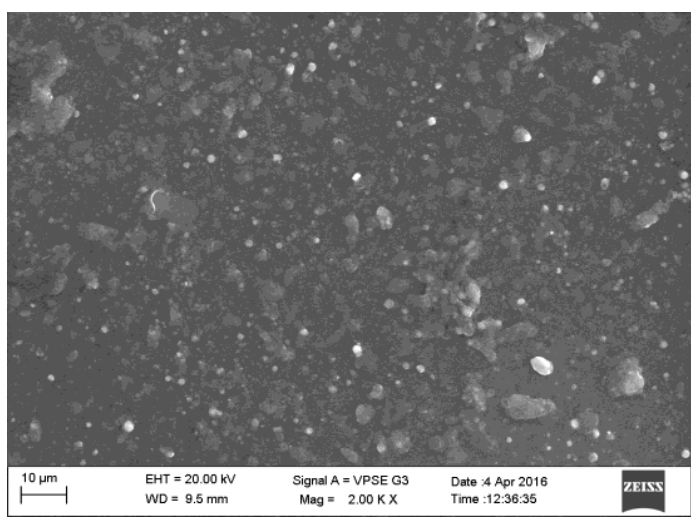

Figure 8 SEM image of 1:3 P:N Blend

Table 2 Bend Gap Values

\begin{tabular}{|l|l|l|}
\hline P:N & Onset Wave Length & Energy Gap $\mathbf{E}_{\mathbf{g}}$ \\
\hline $3: 1$ & $589.62 \mathrm{~nm}$ & $2.10 \mathrm{eV}$ \\
\hline $1: 1$ & $605.32 \mathrm{~nm}$ & $2.04 \mathrm{eV}$ \\
\hline $1: 3$ & $619.96 \mathrm{~nm}$ & $2.0 \mathrm{eV}$ \\
\hline
\end{tabular}

Samples are characterized by UV-visible spectrometer JASCO UV Vis NIR V-670. Pure MEH-PPV film coated on glass which has $\lambda \max =503 \mathrm{~nm}$ and onset of absorption $\lambda$ onset $=578.3 \mathrm{~nm}$. The band gap corresponding to this onset wavelength is $2.1470 \mathrm{eV}$ which agrees with the results quoted in the literature. Semiconducting $\mathrm{TiO}_{2}$ has been extensively studied as a promising material in a variety of applications including dye sensitized solar cells, photocatalysts, and organic photovoltaics. These nanoparticles have the property of good dispersion in the polymer matrix. The incorporation of $\mathrm{TiO}_{2}$ nanospheres can improve the photocurrent 
generation, and the reports are available regarding the improvement in device efficiency. $\mathrm{TiO}_{2}$ is the most promising photoanode material due to its chemical stability, easy control of shape and size, low cost and abundance .Fig2, represents the overlay of UV-Visible spectra for 3:1,1:1 and 1:3 MEH-PPV:TiO2 nano composite samples. Addition of $\mathrm{TiO}_{2}$ nano particles to MEH-PPVhas tuned the absorption spectrum ofMEHPPV. With increase in the doping level, the absorption in the UV region is enhanced followed by the slight reduction in absorption in the Visible range. But there is increased absorption in the region beyond the visible range so that there is net broadening in the absorption spectra. The embedded nano particles in the polymer creates numerous P-N junction between the nanoparticle and polymer matrix, which helps the ease charge separation and improvement in the efficiency. The onset wavelength and band gap calculations are done using the tauc's plot as shown in Fig3. Onset wavelength increases with increase in nano content.and consequently there is decrease in the band gap of the blends. Decrease in band gap inturn will increase the charge conductivity by the sample to fascilitate ease charge migration towards the electrode at which they are collected., Fluoroscence spectra reveal that intensity of light emission has been reduced with increase in the doping level of $\mathrm{TiO} 2$ nanoparticle, There is quenching of fluorescence by increased content of the nano particle in the polymer matrix. Quenched fluorescence is the indication of enhanced photon dissociation into electron and holes which is the primary requisite of a solar cell material. SEM (Scanning Electron Microscopy) images of the samples are depicted in figure 6,fiog7 and fig8. Images indicate the uniform distribution of nano particles in polymer with less aggregation. The optimized 1:3 sample is analysed by X ray Diffraction Studies. The broad peak in the spectrum accounts for the dominance of the amorphous state. Doping the blend with either Gold or Silver nano particle will cause an abrupt increase in the absorption due to Localised Surface Plasmon resonance[7].The construction of the solar cell using the optimized blend is the work under progress.

\section{Conclusion}

We have prepared MEH-PPV: TiO2 photoactive blends having P:N weight ratios 3:1,1:1 and 1:3.UV Visible spectra confirmed the broadening of the absorption curves with increased weight content of the nano particle. Maximum broadening is observed for 1:3 P: $\mathrm{N}$ sample and considered as the best photoactive blend. with Band gap of $2 \mathrm{eV}$. Fluorescence spectra confirmed the quenching of emission with the increased dopimg level and hence the enhanced photon dissociation to create free charges. Almost uniform distribution of the nano particle in the polymer matrix without much aggregation is indicated by SEM images. The active blend is semicrystalline in structure as revealed by XRD studies. The construction of solar cell using the optimized bled is work under progress.

\section{Acknowledgement}

Author is grateful to UGC for financial assistance by sanctioning the Minor research project entitled "Construction and Characterization of an Organic solar cell (OPV) devised from a self made low cost spin coating machine".

Order number- 1419-MRP/14-15/KAKA088/UGC-SWRO, dated 04-02-2015

\section{References}

[1]. T.Ameri, G. Dennier, C. Lungenschmied, C. J. Brabec, Energy Environ. Sci 2009,2,347

[2]. Ritesh Tipnis, Darin Laird, Mathew Mathai, Material Matters 2008, 3.4, 92

[3]. Agnieszka Iwan, Igor tazbir, Maciej Sibinski, Bartosz Boharewicz, Grzegorg Pasciak, Ewa Schab-Balcerzak, materials in semiconductor processing, ELSEVIER, 24(2014) 110-116

[4]. Alexander P, Nikolay O, Alexander K, Galina S, Prog. Polym. Sci. 28, 1701-1753, 2003.

[5]. Annamali P. K., Dilip D., Namrata S. T., Raj P. S., Progress in Polymer Science 34, 479-515, 2009.

[6]. Khan M F S, Alexander A B, Nano Lett. 12, 861-867, 2012

[7]. Uddin A, Yang X, Surface plasmonic effects on organic solar cells.J Nanosci Nanotechnol. 2014 Feb; 14(2):1099119. 